Special Issue of the 6th International Congress \& Exhibition (APMAS2016), Maslak, Istanbul, Turkey, June 1-3, 2016

\title{
Nanocrystalline Nickel Oxide (NiO) Thin Films Grown on Quartz Substrates: Influence Of Annealing Temperatures
}

\author{
F. HajakBari*, M. TAheri AfZali And A. Hojabri \\ Department of Physics, Karaj Branch, Islamic Azad University, Karaj, Iran
}

\begin{abstract}
In the present investigation, nanocrystalline $\mathrm{NiO}$ thin films were prepared by thermal oxidation annealing of DC magnetron sputtered $\mathrm{Ni}$ thin films on quartz substrates. The effect of annealing temperature on the films structural, morphological and optical properties was investigated. The XRD analysis shows that all prepared films were of $\mathrm{NiO}$ with cubic structure and (200) orientation. The thickness of $\mathrm{NiO}$ films was in range of 40-100 $\mathrm{nm}$. The average crystallite size is found to increase from 16 to $36 \mathrm{~nm}$ and the optical band gap energy decreases from 3.62 to $3.38 \mathrm{eV}$ by increasing the annealing temperature from $400{ }^{\circ} \mathrm{C}$ to $600^{\circ} \mathrm{C}$. The AFM and SEM results show that the annealing temperature effectively influences the surface morphology of the films.
\end{abstract}

DOI: $10.12693 /$ APhysPolA.131.417

PACS/topics: 81.40.Tv, 81.07.Bc, 81.15.cd

\section{Introduction}

Nickel oxide $(\mathrm{NiO})$ is a semi-transparent, stable wide direct band-gap material $(3.56 \mathrm{eV})$, which exhibits ptype semiconducting behavior with weak absorption bands $[1-8]$. NiO thin films are attractive materials which can be used as antiferromagnetic layers, as active electrodes in electrochromic devices, p-type layers for UV detectors and functional sensor layer for chemical sensors [1-5]. NiO thin films can be fabricated by different physical and chemical deposition methods, such as sputtering, pulsed laser deposition, thermal evaporation, spray pyrolysis, electron beam evaporation, dip coating, spin coating and electro deposition [1-8]. In the present work, DC magnetron sputtering was employed to prepare nickel (Ni) films. Then, for preparation of $\mathrm{NiO}$ films, the $\mathrm{Ni}$ films were annealed in oxygen atmosphere at different annealing temperatures. The focus of the paper is to investigate the effect of annealing temperature on structural, morphological and optical properties of $\mathrm{NiO}$ thin films.

\section{Experimental details}

In the first step $\mathrm{Ni}$ thin films were deposited on $1 \times 1 \mathrm{~cm}^{2}$ quartz substrates by DC magnetron sputtering method at the same deposition conditions. Prior to films deposition the substrates were cleaned ultrasonically in acetone and ethanol for $15 \mathrm{~min}$. The metal nickel with purity of $99.999 \%$ was used as target and quartz was used for substrates. The base pressure was $5.8 \times 10^{-5}$ mbar and after the introduction of the sputtering gas (Ar 99.999\%) into the chamber the deposition pressure had been reaching $7 \times 10^{-3}$ mbar. The deposition time for all films was $20 \mathrm{~min}$. The target to

\footnotetext{
* corresponding author; e-mail

fatemeh.hajakbari@kiau.ac.ir
}

substrate distance was kept at $4.2 \mathrm{~cm}$. The deposition was done at room temperature. In the second step, the $\mathrm{Ni}$ films were annealed in oxygen atmosphere for 240 min at different temperatures, namely $400^{\circ} \mathrm{C}, 500^{\circ} \mathrm{C}$ and $600^{\circ} \mathrm{C}$. The thickness of $\mathrm{NiO}$ films was in range of 40-100 nm. The crystal structure of the films was characterized by means of X-ray diffraction (XRD) analysis (XRD, Philips, PW-1800, with Co $\mathrm{K}_{\alpha}$ radiation with $\lambda=0.17890 \mathrm{~nm}$ ). The diffraction patterns of films were recorded by varying diffraction angle $2 \theta$ in the range of $10^{\circ}$ to $70^{\circ}$ in steps of $0.02^{\circ}$ and time per step of $1 \mathrm{~s}$. The surface morphology of the deposited films was examined by atomic force microscopy (AFM, Park Scientific Instrument, Auto Probe CP, USA) and scanning electron microscopy (SEM, Hitachi S-4160). The optical transmittance spectra of the films were measured by a spectrophotometer (CARY 500 Scan) in the range of 200-1100 nm.

\section{Results and discussion}

The XRD spectra of the NiO thin films prepared at different annealing temperatures are shown in Fig. 1.

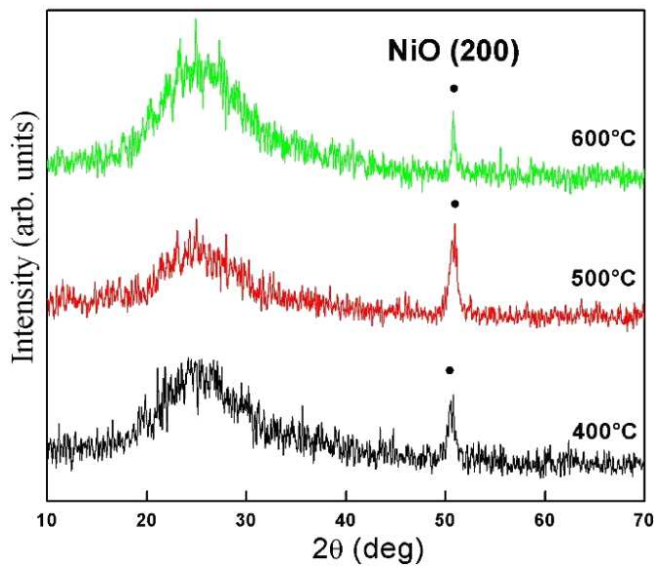

Fig. 1. XRD patterns of $\mathrm{NiO}$ thin films prepared at different annealing temperatures. 
We can observed a broad peak at $2 \theta=24^{\circ}$ that belongs to quartz substrate and another peak at $2 \theta=50.7^{\circ}$, corresponding to the (200) crystal plane of the cubic $\mathrm{NiO}$ phase (JCPDS 78-0643).

The XRD patterns indicate that the $\mathrm{NiO}$ thin films have a single crystalline cubic structure. Additionally the average crystallite size $D$ and microstrain $\varepsilon$ of the $\mathrm{NiO}$ films have been also calculated according to DebyeScherer equation [9] and the results are presented in Table I. According to data from Table I we can observe that the average crystallite size had increased with increase of annealing temperature, which reveals a fine nanocrystalline grain structure. Similar results, showing influence of annealing, were also obtained in [9-11] for silver, molybdenum oxide and zirconium oxide thin films. As the annealing temperature was increased the XRD peaks became sharper, which was due to the increase of particle size and due to the enhancement of the crystallinity. The full width at half maximum (FWHM) was found to decrease with annealing temperature, which may be due to the decrease in the concentration of lattice imperfections.

TABLE I

Summary of structural data obtained for $\mathrm{NiO}$ thin films.

\begin{tabular}{c|c|c|c|c|c}
\hline $\begin{array}{c}\text { Anneal. } \\
\text { temp. } \\
{\left[{ }^{\circ} \mathrm{C}\right]}\end{array}$ & $\begin{array}{c}\text { Phase } \\
\text { composit. }\end{array}$ & $\begin{array}{c}\text { Miler } \\
\text { indices } \\
(\mathrm{hkl})\end{array}$ & $\begin{array}{c}\text { FWHM } \\
{[\mathrm{rad}]}\end{array}$ & $\begin{array}{c}\text { Average } \\
\text { crystallite } \\
\text { size } D[\mathrm{~nm}]\end{array}$ & Microstrain \\
\hline 400 & $\mathrm{NiO}$ & $(200)$ & $10.8 \times 10^{-3}$ & 16 & $5.79 \times 10^{-3}$ \\
500 & $\mathrm{NiO}$ & $(200)$ & $9.7 \times 10^{-3}$ & 18 & $5.20 \times 10^{-3}$ \\
600 & $\mathrm{NiO}$ & $(200)$ & $4.9 \times 10^{-3}$ & 36 & $2.61 \times 10^{-3}$
\end{tabular}

Surface morphology of the films was examined by AFM analysis. Figure 2 gives the 3D images of the AFM scans taken on the scale of $2 \times 2 \mu \mathrm{m}^{2}$. The results show that the annealing temperature has effectively influenced the surface morphology of the films. The films are dense and contain regular surface grains. The root mean square roughness (RMS) of films increases from $1.22 \mathrm{~nm}$ to $4.76 \mathrm{~nm}$ with the increase of annealing temperature from 400 to $600^{\circ} \mathrm{C}$.

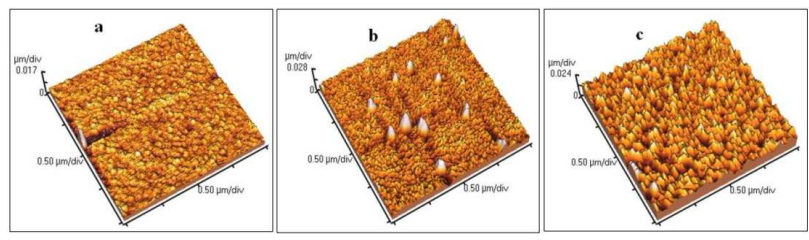

Fig. 2. 3D AFM images of $\mathrm{NiO}$ thin films prepared at different annealing temperatures: (a) $400{ }^{\circ} \mathrm{C}$, (b) $500^{\circ} \mathrm{C}$ and (c) $600{ }^{\circ} \mathrm{C}$.

The morphological characterization was also performed using SEM analysis. Figure 3 shows the SEM images of the $\mathrm{NiO}$ thin films annealed at different temperatures. We can observe that the surface of the films prepared at annealing temperature of $400^{\circ} \mathrm{C}$ (Fig. 3a) consists of regular and small grains and the increase of annealing temperature up to $600{ }^{\circ} \mathrm{C}$ (Fig. 3b and c ) has led to agglomeration of grains and to an increase of the particles sizes.

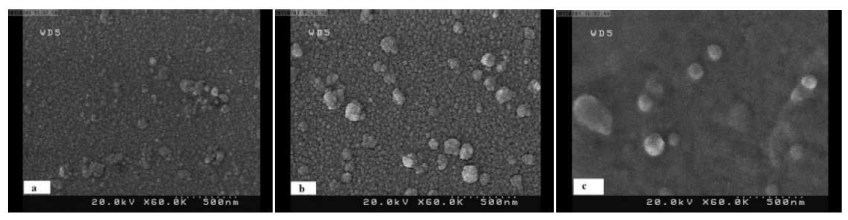

Fig. 3. SEM micrographs of $\mathrm{NiO}$ films for different annealing temperatures: (a) $400{ }^{\circ} \mathrm{C}$, (b) $500^{\circ} \mathrm{C}$ and (c) $600^{\circ} \mathrm{C}$.

The transmittance spectra of the $\mathrm{NiO}$ thin films at wavelengths in range of $200-1100 \mathrm{~nm}$ are shown in Fig. 4. The optical transmittance of prepared films shows that the transmittance increases at elevated annealing temperatures due to improving crystalline microstructure, which results in lesser defect scattering. The optical absorption coefficient $\alpha$ was evaluated from the optical transmittance $T$ using the relation $\alpha=-\ln T / d$, where $d$ is the thickness of films. The optical band gap $E_{\mathrm{g}}$ of the $\mathrm{NiO}$ films prepared at different annealing temperatures was calculated from plot of $(\alpha h \nu)^{2}$ versus photon energy $h \nu$ by extrapolating the linear portion to zero absorption $(\alpha=0)$ [12].

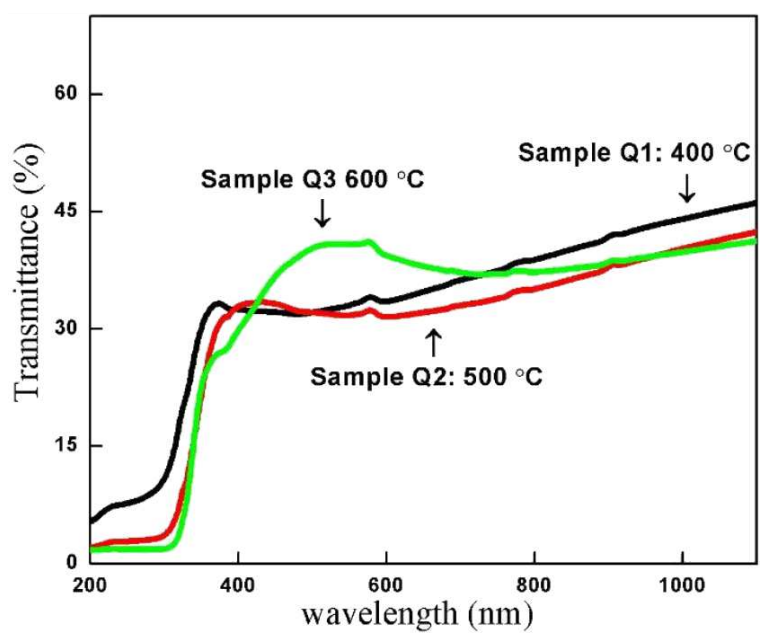

Fig. 4. Transmittance spectra of the $\mathrm{NiO}$ thin films prepared at different annealing temperatures.

The plots of $(\alpha h \nu)^{2}$ versus photon energy $h \nu$ for $\mathrm{NiO}$ films prepared at different annealing temperatures of 400 , 500 and $600{ }^{\circ} \mathrm{C}$ are shown in Fig. 5, curves a, b and c, respectively. The deduced $E_{\mathrm{g}}$ of $\mathrm{NiO}$ films was found to be $3.62,3.41$ and $3.38 \mathrm{eV}$ for the films annealed at 400 , 500 and $600{ }^{\circ} \mathrm{C}$, respectively. These $E_{\mathrm{g}}$ values are in good agreement with the values reported in $[4,7,8,13]$ for $\mathrm{NiO}$ thin films. The decrease of $E_{\mathrm{g}}$ with annealing temperature may be attributed to the increase of crystallite size and decrease of defect sites concentration [13, 14]. 


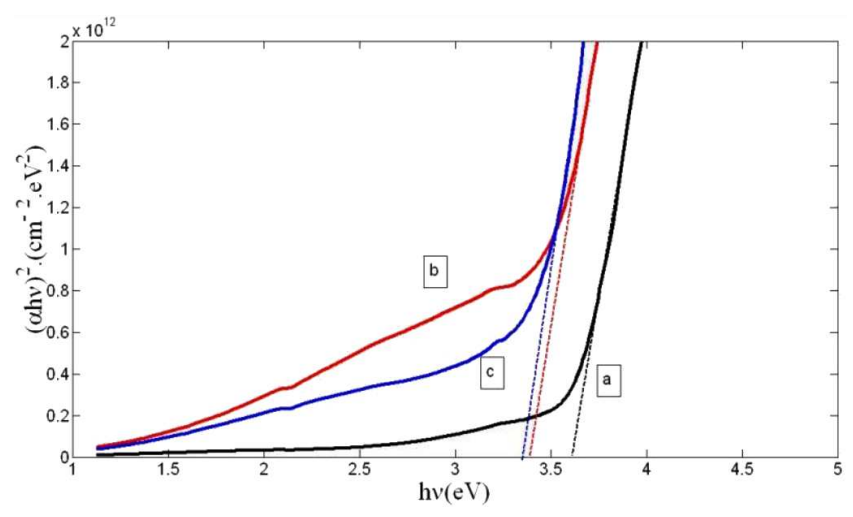

Fig. 5. The plot of $(\alpha h \nu)^{2}$ versus photon energy $h \nu$ for the $\mathrm{NiO}$ films prepared at different annealing temperatures: (a) $400{ }^{\circ} \mathrm{C}$, (b) $500^{\circ} \mathrm{C}$ and (c) $600^{\circ} \mathrm{C}$.

\section{Conclusions}

The nanocrystalline $\mathrm{NiO}$ thin films with cubic structure with (200) orientation were successfully prepared on quartz substrates by thermal annealing of DC magnetron sputtered Ni films. The average crystallite size was in range of $16-36 \mathrm{~nm}$. The SEM and AFM results exhibit that the surface morphology of the $\mathrm{NiO}$ thin films is influenced by annealing temperature. The RMS roughness of films has increased from $1.22 \mathrm{~nm}$ to $4.76 \mathrm{~nm}$ by increasing the annealing temperature from $400^{\circ} \mathrm{C}$ to $600{ }^{\circ} \mathrm{C}$. The optical studies exhibit that the transmittance of the films increases with annealing temperature and that the optical band gap was in range of $3.38-3.62 \mathrm{eV}$.

\section{Acknowledgments}

This work was supported by Islamic Azad University, Karaj Branch, Karaj, Iran.

\section{References}

[1] A. Mallikarjuna Reddy, A. Sivasankar Reddy, P. Sreedhara Reddy, Vaccum 85, 949 (2011).

[2] S. Baran, A. Hoser, B. Penc, A. Szytula, Acta Phys. Pol. A 129, 35 (2016).

[3] V. Verma, M. Katiyar, Thin Solid Films. 527, 369 (2013).

[4] E.R. Shaaban, M.A. Kaid, M.G.S. Ali, J. Alloys. Comp. 613, 324 (2014).

[5] A.M. Soleimanpour, Y. Hou, A.H. Jayatissa, Sens. Actuators, B-Chem. 182, 125 (2013).

[6] M.L. Grilli, I.D. Sarcina, S. Bossi, A. Rinaldi, L. Pilloni, A. Piegari, Thin Solid Films. 594, 261 (2015).

[7] V. Gowthami, M. Meenakshi, P. Perumal, R. Sivakuma, C. Sanjeeviraja, Mater. Sci. Semicond. Process. 27, 1042 (2014).

[8] A. Karpinski, N. Ouldhamadouche, A. Ferrec, L. Cattin, M. Richard-Plouet, L. Brohan, M.A. Djouadi, P.-Y. Jouan, Thin Solid Films 519, 5767 (2011).

[9] F. Hajakbari, M. Ensandoust, Acta Phys. Pol. A 129, 680 (2016).

[10] A. Hojabri, F. Hajakbari, A. Emami Meibody, M.A. Moghri Moazzen, Acta Phys. Pol. A 123, 307 (2013).

[11] A. Hojabri, S. Pourmohammad, Acta Phys. Pol. A 129, 647 (2016).

[12] F. Hajakbari, F. Shafienejad, Jpn. J. Appl. Phys. 55, 035503 (2016).

[13] Y. Akahun, T. Cayir, J. Alloys. Comp. 625, 144 (2015).

[14] A. Hojabri, J. Theor. Appl. Phys. 10, 219 (2016). 